\title{
Identification of Rice Blast Fungal Elicitor-Responsive Genes by Differential Display Analysis
}

\author{
Cha Young Kim, ${ }^{1}$ Sung-Ho Lee, ${ }^{2}$ Hyeong Cheol Park, ${ }^{1}$ Chang Gyu Bae, ${ }^{1}$ Yong Hwa Cheong, ${ }^{1}$ \\ Young Ju Choi, ${ }^{3}$ Chang-deok Han,, ${ }^{2}$ Sang Yeol Lee, ${ }^{1}$ Chae Oh Lim, ${ }^{2}$ and Moo Je Cho ${ }^{1,2}$ \\ ${ }^{1}$ Department of Biochemistry, ${ }^{2}$ Plant Molecular Biology and Biotechnology Research Center, Gyeongsang \\ National University, Chinju 660-701, ${ }^{3}$ Department of Food and Nutrition, Silla University, Pusan 616-060, \\ Korea \\ Accepted 8 December 1999.
}

In order to study molecular interactions that occur between rice and rice blast fungus upon infection, we isolated fungal elicitor-responsive genes from rice (Oryza sativa cv. Milyang 117) suspension-cultured cells treated with fungal elicitor prepared from the rice blast fungus (Magnaporthe grisea) employing a method that combined mRNA differential display and cDNA library screening. Data base searches with the isolated cDNA clones revealed that the OsERG1 and OsERG2 cDNAs share significant similarities with the mammalian $\mathrm{Ca}^{2+}$-dependent lipid binding (C2) domains. The OSCPX1 cDNA is highly homologous to peroxidases. The OsHin1 cDNA exhibits homology to the tobacco hinl gene, whose expression is induced by avirulent pathogens. The OsLPLI and OsMEK1 cDNAs share homologies with lysophospholipases and serine/threonine mitogen-activated protein (MAP) kinase kinases, respectively. The OsWRKY1 and OsEREBPI cDNAs are homologous to transcription factors, such as the WRKY protein family and the AP2/EREBP family, respectively. Transcripts of the OsERG1, OsHin1, and $O$ SMEK1 genes were specifically elevated only in response to the avirulent race KJ301 of the rice blast fungus. Our study yielded a number of elicitor-responsive genes that will not only provide molecular probes, but also contribute to our understanding of host defense mechanisms against the rice blast fungus.

Plants protect themselves against pathogen attack by launching both localized and systemic defense responses such as the generation of reactive oxygen species, the accumulation of phytoalexins, and the synthesis of pathogenesis-related proteins that include hydrolytic enzymes (Dixon and Lamb 1990; Yang et al. 1997).

When a pathogen penetrates plant tissue, the plant cells perceive signals coming from the pathogen. These signals, known as elicitors, can be compounds such as oligosaccharides, pro-

Corresponding author: Moo Je Cho: Telephone: +82-591-751-5957; Fax: +82-591-759-9363; E-mail: mjcho@ nongae.gsnu.ac.kr

Cha Young Kim and Sung-Ho Lee have contributed equally to this work and should be considered co-first authors. teins, and glycoproteins that are released from fungal as well as plant cell walls and are transmitted to give activation of defense gene expression via intracellular signaling cascades (Dixon and Lamb 1990; Ryan and Farmer 1991). Elicitors specifically bind to receptors on the plasma membrane and trigger the signaling events necessary for the onset of defense responses (Basse et al. 1993; Nurnberger et al. 1995).

Fungal diseases of rice, such as rice blast and sheath blight, which are caused by Magnaporthe grisea and Rhizoctonia solani, respectively, remain major factors in limiting rice productivity worldwide (Xu et al. 1996). Among the immediate goals of research is, therefore, the development of appropriate defense systems capable of enhancing resistance against these pathogens. In this endeavor, it is important to understand the molecular mechanisms of the natural defense responses of rice (Masuta et al. 1991). The molecular mechanism of the elicitor-mediated signal transduction pathway in plants is not yet fully understood. Furthermore, though many disease resistance genes of various dicotyledonous plants have been cloned, not much has yet been reported about reliable resistance genes in rice. Suspension-cultured cells, because of their biochemical and physiological homogeneity, offer a better system than whole plants in which to study elicitor-mediated signaling (Masuta et al. 1991). Elicitors emanating from fungal cell walls can provoke many of the defense responses seen in plants and also in cultured cells (Cote and Hahn 1994; Kim et al. 1998). The differential display polymerase chain reaction (PCR) method in combination with polyacrylamide gel electrophoresis allows comparison of PCR-amplified cDNA fragments between two or more mRNA populations, and has been very successful in the identification of differentially expressed genes (Liang and Pardee 1992). The identification of differentially accumulated mRNAs has helped not only in the understanding of gene function but also in the understanding of the underlying molecular mechanisms in a particular biological system.

We set out to study the pathogen signal transduction pathway that occurs in rice (Oryza sativa L. 'Milyang 117') upon infection by the fungal pathogen Magnaporthe grisea. As a first step, we established optimal experimental conditions for both mRNA differential display and direct cDNA library screening. Then we cloned and sequenced a large number of 
elicitor-responsive genes isolated from a rice cell culture. We treated the embryogenic suspension-cultured rice cells with fungal elicitor (50 $\mu \mathrm{g}$ of glucose equivalents per $\mathrm{ml}$ ) for 30 and $60 \mathrm{~min}$ before isolating total cellular RNA (Ohira et al. 1973). The oligosaccharide fungal elicitor was prepared from the cell wall fraction of the rice blast fungus Magnaporthe grisea $\mathrm{KJ} 301$, which is the avirulent strain to the rice cultivar Milyang 117, by the method of Doke and Furuichi (1982). One hundred and twenty reverse transcription (RT)-PCRs

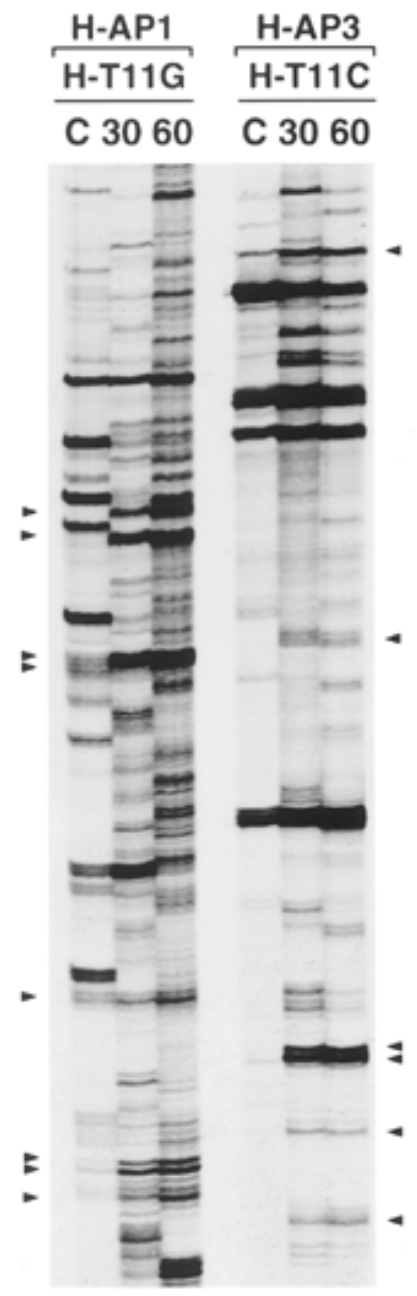

Fig. 1. Differential display patterns of total RNA from water-treated (C) and fungal elicitor-treated (30 and $60 \mathrm{~min}$ ) rice suspension cells using arbitrary 5' primers and 3' anchored oligo-dT primers. To remove contamination of the chromosomal DNA from isolated total RNA, $50 \mu \mathrm{g}$ of total cellular RNA was incubated for $30 \mathrm{~min}$ at $37^{\circ} \mathrm{C}$ with 10 units of GH-DNase I according to the manufacturer's protocol (Message Clean Kit; GenHunter, Brookline, MA). One hundred nanograms of each total RNA sample was reverse transcribed with the $3^{\prime}$ anchored primers $(\mathrm{H}-$ T11G, 5'-AAGCTT TTTTTTTTTTTG-3'; H-T11C-3') and the resultant cDNAs were amplified in the presence of ${ }^{32} \mathrm{P}$-dATP with the same $3^{\prime}$ primer and either H-AP1 (5'-AAGCTTGATTGCC-3') or H-AP3 (5'AAGCTTTGGTCAG- $3^{\prime}$ ) as the $5^{\prime}$ primer with RNA Image Kit (GenHunter, Brookline, MA). The polymerase chain reaction products were separated on a $6 \%$ denaturing polyacrylamide gel. The gel was then dried and exposed to X-ray film. Positive fungal elicitor-induced display bands (arrowheads) were excised from the gel and re-amplified according to the manufacturer's specifications. Fungal elicitor (50 $\mu \mathrm{g}$ of glucose equivalents per $\mathrm{ml}$ ) was added to the growth medium, and incubated for 30 and $60 \mathrm{~min}$. were performed for each RNA extract with the combinations of $405^{\prime}$ arbitrary 13-mer-primers (H-AP1-H-AP40) and three different $3^{\prime}$ one-base-anchored primers (H-T11G, H-T11A, HT11C) according to the manufacturer's protocol (RNA Image Kit; GenHunter, Brookline, MA). An example of the mRNA differential display patterns is shown in Figure 1. In each case, RNA from elicitor-treated cells (30 and 60 min) was compared with RNA from water-treated cells as a control. After separation of the cDNAs on a DNA sequencing gel, we were able to identify approximately 800 cDNA fragments upregulated differentially and ranging from 100 to $350 \mathrm{bp}$ in length. After elution from the gel, these bands were reamplified with the same set of primers used for the differential display under the same PCR conditions without radioactive nucleotides.

To evaluate the expression patterns of the re-amplified cDNA fragments in response to fungal elicitor, all $800 \mathrm{cDNA}$

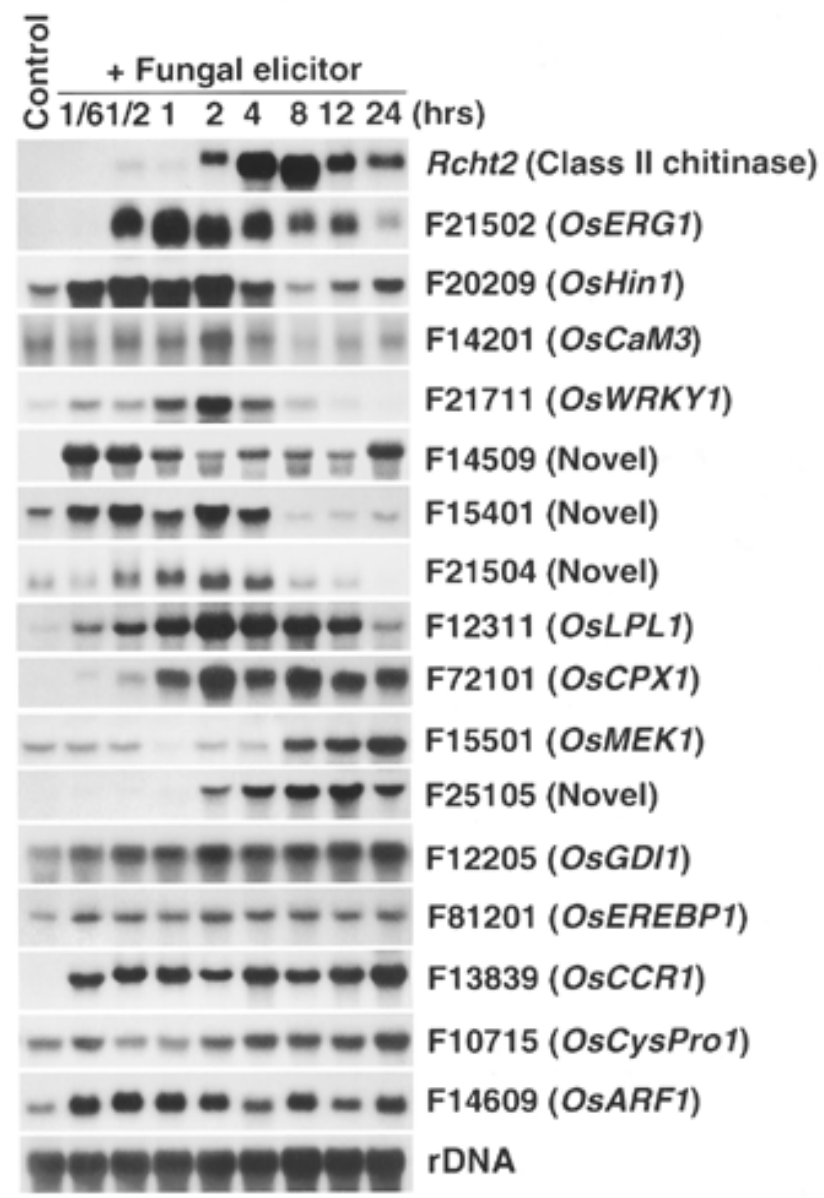

Fig. 2. Northern (RNA) blot analysis of total RNA isolated from watertreated (control) and elicitor-treated (10 and $30 \mathrm{~min}, 1,2,4,8,12$, and $24 \mathrm{~h}$ ) cells with the elicitor-responsive genes isolated by both differential display and library screening as probes. Fungal elicitor (50 $\mu \mathrm{g}$ of glucose equivalents per $\mathrm{ml}$ ) was added to the growth medium and incubations were carried out for the indicated lengths of time. The differential expression patterns of the elicitor-responsive genes observed upon treatment with fungal elicitor were shown. The rice chitinase Rcht 2 gene was used as a positive control (Kim et al. 1998). A 20- $\mu$ g aliquot of total RNA was loaded per lane. RNA equal loading was checked by hybridization of the blot with a probe corresponding to the rice $18 \mathrm{~S}$ ribosomal RNA (rDNA). 
fragments obtained from differential display were tested for transcriptional induction by RNA gel blotting. The majority of cDNA bands were present in equal abundance in the control and elicitor-treated cells. Among them, 70 cDNAs showed differential accumulation of transcript in response to elicitor treatment. All $70 \mathrm{cDNAs}$ were separately used as probes for cDNA library screening. In general, direct cloning of PCRamplified cDNAs into a plasmid vector is prone to produce two or more unrelated cDNAs of the same size in the reamplified PCR product. To circumvent this problem, we directly screened a $\lambda$ ZAP cDNA library constructed from rice suspension-cultured cells treated with fungal elicitor, with the PCR re-amplified cDNA fragments as probes. The probes were ${ }^{32} \mathrm{P}$-labeled by random primed labeling.

By analysis of 5'- and 3'-nucleotide sequences of positive cDNA clones isolated from library screening with the BLAST (basic local alignment search tool) program (Altschul et al. 1990), we obtained 115 different cDNA clones. From them we chose 16 cDNA clones for further analysis, because only these clones showed accumulation of transcripts by treatment of the fungal elicitor upon Northern (RNA) blot analysis (Fig. 2). Table 1 summarizes the sequencing results for the cDNAs obtained by the combination of mRNA differential display and library screening.

The clones F21502 (OsERG1) and F21503 (OsERG2) exhibited homology to a novel protein from Zea mays (U64437). Moreover, the OsERG1 and OsERG2 clones also shared significant homology with mammalian $\mathrm{Ca}^{2+}$-dependent lipid binding (CaLB or $\mathrm{C} 2$ ) domains. The OsERG1 and OsERG2 cDNAs have open reading frames of 480- and 471-bp encoding putative proteins of 159 and 156 amino acids, respectively, each containing a single $\mathrm{C} 2$ domain. In contrast to the large number of C2-containing proteins known in animals, very few C2 domain proteins have been reported in plants. In animal cells, the $\mathrm{C} 2$ domain proteins are most likely to be involved in a variety of signal transduction pathways. The $\mathrm{C} 2$ domains in
PKC, PLC, cPLA2, synaptotagmin, GAP, and Ras-GTPase play regulatory roles in mediating the $\mathrm{Ca}^{2+}$-dependent recruitment of these enzymes to the phospholipid membrane (Kopka et al. 1998). In contrast, no function has so far been assigned to $\mathrm{C} 2$ domains in plant proteins. The presence of a $\mathrm{C} 2$ domain within the sequence of OsERG1 and OsERG2 suggests that the OsERG1 and OsERG2 proteins have an as yet unidentified function that is regulated by $\left[\mathrm{Ca}^{2+}\right]$ and/or phospholipid in response to elicitor stimuli. The F20209 (OsHinl) clone shares significant homology with hinl from tobacco, a gene that is rapidly activated by both harpins and an avrPto-mediated signal (Gopalan et al. 1996). The F14201 (OsCaM3) clone was $100 \%$ identical to the novel rice calmodulin CaM61 with the C-terminal extension of 38 amino acids (U37936). F21711 (OsWRKY1) exhibited high homology to the WRKY protein family (Rushton et al. 1996). The WRKY proteins are a novel type of transcription factors with zinc finger domains that bind to the $\mathrm{W}$ box (TTGACC motif) located in the promoter sequence of plant defense genes (Rushton et al. 1996). The F12311 (OsLPL1) clone has significant homology to the lysophospholipases from Arabidopsis. Lysophospholipases are widely distributed enzymes that hydrolyze lysophospholipids, the detergent-like intermediates in phospholipid metabolism, and therefore regulate the lysophospholipid levels in cells (Wang et al. 1997). The F72101 (OsCPX1) clone showed homology to plant peroxidases that are involved in several plant defense responses including lignification and cross-linking of cell wall proteins (Bradley et al. 1992). The F15501 (OsMEK1) clone revealed most homology to a novel serine/threonine protein kinase, $P k p A$, from the filamentous fungus Phycomyces blakesleeanus, whose sequence is related to a number of mitogen-activated protein (MAP) kinase kinase proteins. The $O s M E K 1$ cDNA encodes a putative MAP kinase kinase. The F12205 and F12212 clones encode an Rab GDP dissociation inhibitor (RabGDI) with more than $50 \%$ identity to the RabGDIs of various organisms

Table 1. Sequence analysis of differentially expressed genes isolated from elicitor-treated rice cells by differential display and cDNA library screening ${ }^{\mathrm{a}}$

\begin{tabular}{|c|c|c|c|c|c|}
\hline Clone & GenBank accession no. & cDNA size $^{b}$ & Sequence homology ${ }^{c}$ & $\begin{array}{l}\text { Data base match } \\
{\text { (accession no. })^{\text {d }}}^{\text {accion }}\end{array}$ & $\begin{array}{l}\text { Identity } \\
\text { score }^{\mathrm{e}}\end{array}$ \\
\hline F21502 & U95135 & 851 & Novel protein (OsERG1) & Maize (U64437) & X53 \\
\hline F21503 & U95136 & 745 & Novel protein (OsERG2) & Maize (U64437) & X164 \\
\hline F20209 & AF039532 & 1067 & hin1 $(O \sin 1)$ & Tobacco (Y07563) & X195 \\
\hline F14201 & AF090687 & 926 & Calmodulin (OsCaM3) & Rice (U37936) & $\mathrm{X} 412$ \\
\hline F21711 & AF090699 & 1714 & SPF1-like DNA-binding protein (OsWRKY1) & Tobacco (AF096299) & $\mathrm{X} 216$ \\
\hline F14509 & AF071063 & ND & Unknown protein & Rice (D49093) & X31 \\
\hline F15401 & AF061643 & 687 & No match & & \\
\hline F21504 & AF090698 & 710 & Novel protein (OsERG3) & Maize (U64437) & $\mathrm{X} 279$ \\
\hline F12311 & AF039531 & 1224 & Lysophospholipase (OsLPL1) & Arabidopsis (U95973) & X196 \\
\hline F72101 & AF019743 & 1333 & Peroxidase $(O s C P X 1)$ & Arabidopsis (X98318) & $\mathrm{X} 168$ \\
\hline F15501 & AF080436 & 2432 & Serine/threonine protein kinase pkpA ( OsMEK1) & Fungus (Z46636) & $\mathrm{X} 235$ \\
\hline F25105 & AF061113 & 1873 & No match & & \\
\hline F12205 & AF016896 & 1770 & GDP-associated inhibitor ( $O s G D I 1)$ & Arabidopsis (Y07961) & X299 \\
\hline F12212 & AF016897 & 1770 & GDP-associated inhibitor ( $O s G D I 2)$ & Arabidopsis (Y07961) & X202 \\
\hline F81201 & U95216 & 1612 & EREBP $(O s E R E B P 1)$ & Arabidopsis (AF003105) & X138 \\
\hline F13839 & AF080437 & ND & Cinnamoyl-CoA reductase ( $O s C C R l)$ & Cider tree (X97433) & $\mathrm{X} 130$ \\
\hline F10715 & AF092949 & ND & Cysteine proteinase (OsCysProl) & Maize (D45420) & $\mathrm{X} 241$ \\
\hline F14609 & AF012896 & 840 & ADP-ribosylation factor ( $O s A R F 1)$ & Arabidopsis (P36397) & X197 \\
\hline
\end{tabular}

${ }^{a}$ Sequence comparisons were performed with the BLAST search from the National Center for Biotechnology Information (NCBI, USA).

${ }^{b}$ Determined by sequencing predicted full-length cDNA inserts except the F21711, F14509, F13839, and F10715 clones.

${ }^{c}$ Sequence homology according to the NCBI BLAST search results (gene designations in brackets refer to gene names isolated from elicitor-treated rice cells).

${ }^{\mathrm{d}}$ GenBank/EMBL/SwissProt accession number for known sequence with the closest match according to the NCBI BLAST search.

${ }^{\mathrm{e}}$ Identity score of each positive clone with known sequences according to the NCBI BLAST search (BLASTX program). 
(Garrett et al. 1994). The F81201 (OsEREBP1) clone showed high similarity to AP2/EREBP transcription factors of plants. These are DNA binding proteins specific for the GCC box (TAAGAGCCGCC motif) that is required for ethylene responsiveness of several basic pathogenesis-related (PR) protein genes (Okamuro et al. 1997). Clone F13839 (OsCCRl) encodes a putative cinnamoyl-CoA reductase (CCR). CCR catalyzes the reduction of CoA esters of hydroxycinnamic acids to cinnamyl alcohols derived from the phenylpropanoid metabolism during lignin biosynthesis. Lignin plays an important role in structural support and in defense responses (Douglas 1996). Clones F14509, F15401, F21504, and F25105 did not reveal any significant sequence similarities to known genes in the data bases and are thus considered novel.

To determine the expression patterns of the fungal elicitorresponsive genes isolated from rice, the time course of their expression in response to fungal elicitor was examined by Northern blot analysis (Fig. 2). The transcript levels of $O s$ ERG1, OsHin1, OsCaM3, OsWRKY1, and F14509, F15401, F21504, and OsLPL1 rose rapidly but transiently within 0.5 to $2 \mathrm{~h}$ of the elicitor addition, decreasing 8 to $12 \mathrm{~h}$ after the treatment. Thus, these elicitor-responsive genes could be used as molecular probes for the analysis of early events in the pathogen-plant cell interaction. In contrast, the transcripts of OsCPX1, OsMEK1, and F25105 were observed at increased levels at a late time after elicitation. A third pattern of expres-

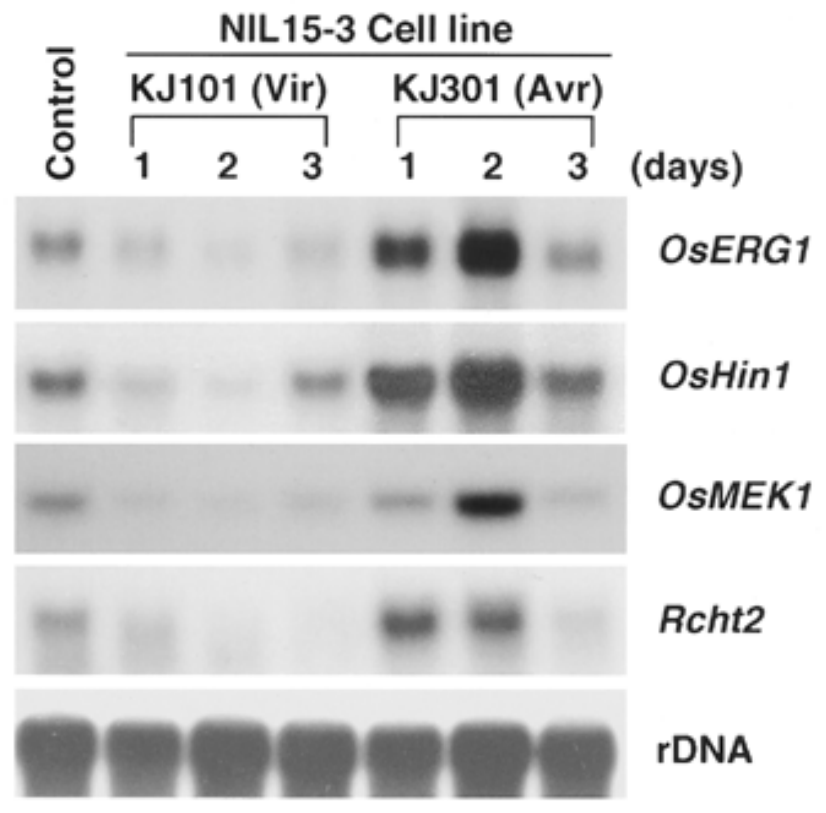

Fig. 3. Avirulence-specific induction of transcripts of elicitor-responsive genes in response to rice blast fungus infection. A nearly isogenic rice line (NIL15-3) was used to monitor the expression of OsERG1, OsHin1, and $O s M E K 1$ in response to infection with Magnaporthe grisea race KJ301 (avirulent) or race KJ101 (virulent). Rice cells in suspension culture were infected with fungal spores $\left(5 \times 10^{5}\right.$ spores per $\left.\mathrm{ml}\right)$ and incubated for the lengths of time indicated. The rice chitinase Rcht 2 gene was used as a positive control (Kim et al. 1998). Twenty micrograms of total RNA from each culture was used for Northern (RNA) blot hybridization with each of the cloned cDNAs for OsERG1, OsHin1, and $O s M E K 1$. RNA equal loading was checked by hybridization of the blot with a probe corresponding to the rice $18 \mathrm{~S}$ ribosomal RNA (rDNA). sion in response to fungal elicitor was seen for the OsGDII, OsEREBP1, OsCCR1, OsCysProl, and OsARF1 transcripts. Induction of these transcripts occurred to a lesser extent but was sustained for up to $24 \mathrm{~h}$ after treatment. As a positive control, we monitored the expression of rice class II chitinase (Rcht2) in response to fungal elicitor (Fig. 2), since treatment with the fungal elicitor effectively induced the accumulation of $R$ cht 2 transcripts in the rice suspension-cultured cells (Kim et al. 1998).

We have established the optimal condition for the use of cultured rice cells to study avr/vir interactions that occur between rice and rice blast fungus upon infection. Rice cells in suspension culture were infected with fungal spores $\left(5 \times 10^{5}\right.$ spores per $\mathrm{ml}$ ). The viability of suspension cells after inoculation was checked by TTC (2,3,5-triphenyl tetrazolium chloride) staining assay (Steponkus and Lanphear 1967). To examine whether the transcript of the elicitor-responsive genes correlated with virulence, the expression kinetics of OsERG1, OsHin1, OsMEK1, and Rcht2 (positive control) were examined in cultured cells inoculated with either $M$. grisea race KJ301 (avirulent) or race KJ101 (virulent). As seen in Figure 3, transcripts of the OsERG1, OsHin1, and OsMEK1 genes accumulated specifically in cells inoculated with the avirulent race, but not with the virulent race. The Rcht 2 chitinase expression pattern was similar to that of these three elicitorresponsive genes.

We conclude that the elicitor-responsive genes isolated from rice make good candidates for genes that are involved in plant defense responses. They can therefore be used as molecular probes to study elicitor-mediated signal transduction pathways.

\section{ACKNOWLEDGMENTS}

We thank K. Y. Kang for supplying us Magnaporthe grisea isolates of race KJ101 and KJ301 with nearly isogenic rice line (NIL15-3). This work was supported by grants from the Ministry of Science and Technology (99-G-08-02-06), from the Ministry of Agriculture and Forestry (298049-4) to M. J. C., and from KOSEF to the Plant Molecular Biology and Biotechnology Research Center.

\section{LITERATURE CITED}

Altschul, S. F., Gish, W., Miller, W., Myers, E. W., and Lipman, D. J. 1990. Basic local alignment search tool. J. Mol. Biol. 215:403-410.

Basse, C. W., Fath, A., and Boller, T. 1993. High affinity binding of a glycopeptide elicitor to tomato cells and microsomal membranes and displacement by specific glycan suppressors. J. Biol. Chem. 268: 14724-14731.

Bradley, D. J., Kjellbom, P., and Lamb, C. J. 1992. Elicitor- and woundinduced oxidase cross-linking of a plant cell wall proline-rich protein: A novel, rapid defense response. Cell 70:21-30.

Cote, F., and Hahn, M. G. 1994. Oligosaccharins: Structures and signal transduction. Plant Mol. Biol. 26:1379-1411.

Dixon, R. A., and Lamb, C. J. 1990. Molecular communication in interactions between plants and microbial pathogens. Annu. Rev. Plant Physiol. Plant Mol. Biol. 41:339-367.

Doke, N., and Furuichi, N. 1982. Response of protoplasts to hyphal wall components in relationship to resistance of potato to Phytophthora infestans. Plant Pathol. 2:23-30.

Douglas, C. J. 1996. Phenylpropanoid metabolism and lignin biosynthesis: From weeds to trees. Trends Plant Sci. 1:171-178.

Garrett, M. D., Zahner, J. E., Cheney, C. M., and Novick, P. J. 1994. GDI1 encodes a GDP dissociation inhibitor that plays an essential role in the yeast secretary pathway. EMBO J. 13:1718-1728.

Gopalan, S., Wei, W., and He, S. Y. 1996. Hrp gene-dependent induction 
of hin1: A plant gene activated rapidly by both harpins and avrPto gene-mediated signal. Plant J. 10:591-600.

Kim, C. Y., Gal, S. W., Choe, M. S., Jeong, S. Y., Lee, S. I., Cheong, Y H., Lee, S. H., Choi, Y. J., Han, C.-d., Kang, K. Y., and Cho, M. J. 1998. A new class II rice chitinase, Rcht2, whose induction by fungal elicitor is abolished by protein phosphatase 1 and $2 \mathrm{~A}$ inhibitor. Plant Mol. Biol. 37:523-534.

Kopka, J., Pical, C., Hetherington A. M., and Muller-Rober, B. 1998. $\mathrm{Ca}^{2+} /$ phospholipid-binding $\left(\mathrm{C}_{2}\right)$ domain in multiple plant proteins: Novel components of the calcium-sensing apparatus. Plant Mol. Biol. 36:627-637.

Liang, P., and Pardee, A. B. 1992. Differential display of eukaryotic messenger RNA by means of the polymerase chain reaction. Science 257:967-971.

Masuta, C., Van den Bulcke, M., Bauw, G., Van Montagu, M., and Caplan, A. B. 1991. Differential effects of elicitors on the viability of rice suspension cells. Plant Physiol. 97:619-629.

Nurnberger, T., Nennstiel, D., Hahlbrock, K., and Scheel, D. 1995. Covalent cross-linking of the Phytophthora megasperma oligopeptide elicitor to its receptor in parsley membranes. Proc. Natl. Acad. Sci. USA 92:2338-2342.

Ohira, K., Ojima, K., and Fujiwara, A. 1973. Studies on the nutrition of rice cell culture. I. A simple, defined medium for rapid growth in sus- pension culture. Plant Cell Physiol. 14:1113-1121.

Okamuro, J. K., Caster, B., Villarroel, R., Van Montagu, M., and Jofuku, K. D. 1997. The AP2 domain of APETALA2 defines a large new family of DNA binding proteins in Arabidopsis. Proc. Natl. Acad. Sci. USA 94:7076-81.

Rushton, P. J., Torres, J. T., Parniske, M., Wernert, P., Hahlbrock, K., and Somssich, I. E. 1996. Interaction of elicitor-induced DNA-binding proteins with elicitor response elements in the promoters of parsley PR1 genes. EMBO J. 15:5690-5700.

Ryan, C. A., and Farmer, E. E. 1991. Oligosaccharide signals in plants: A current assessment. Annu. Rev. Plant Physiol. Plant Mol. Biol. 42: 651-674.

Steponkus, P. L., and Lanphear, F. O. 1967. Refinement of the triphenyl tetrazolium chloride method of determining cold injury. Plant Physiol. 42:1423-1426.

Wang, A., Deems, R. A., and Dennis, E. A. 1997. Cloning, expression, and catalytic mechanism of murine lysophospholipase I. J. Biol. Chem. 272:12723-12729.

Xu, Y., Zhu, Q., Panbangred, W., Shirasu, K., and Lamb, C. 1996. Regulation, expression and function of a new basic chitinase gene in rice (Oryza sativa L.). Plant Mol. Biol. 30:387-401.

Yang, Y., Shah, J., and Klessig, D. F. 1997. Signal perception and transduction in plant defense responses. Genes Dev. 11:1621-1639. 